\title{
THE INSTITUTE OF MOLECULAR MEDICINE, UNIVERSITY OF OXFORD
}

\author{
Professor Sir David Weatherall, Honorary Director
}

The Institute of Molecular Medicine (IMM) was established to address the problems of applying basic research in molecular and cell biology to the study of human disease in a clinical setting. Recent advances in molecular and cell biology have enormous potential for medical research and practice. They have implications for our understanding of the causes and treatment of many of the common intractable diseases of both the developing and the developed world. Over the longer term, this new field may well revolutionize the pharmaceutical industry and provide it with completely new approaches to the development of drugs and other forms of therapy. In particular, it has the potential for unraveling the causes of some of the major unsolved mysteries of modern medicine: heart disease, hypertension, psychiatric illness, cancer, and the like. And it is already helping us start to understand some of the mysteries of development and aging.

The United Kingdom was slow to see the clinical importance of these new developments in the basic sciences. The technology is complex, and there were few centers where clinicians could be trained in its direct application to the kinds of problems that interested them. Such training can best be achieved in a setting where there is a blend of clinical and nonclinical scientists with expertise in the molecular sciences. However, it has always been difficult to recruit top class nonclinical scientists into clinical departments, because such settings rarely have the facilities or staff to attract young molecular biologists, who prefer to work in basic science departments; they often feel isolated in a clinical setting. Furthermore, there are formidable financial problems in providing every clinical department in medical school with the equipment and expertise to compete internationally in this rapidly growing field.

With these difficulties in mind, at the end of 1983, the Medical Research Council (MRC) was approached with the notion that we should set up an institute in the Oxford Clinical School which would house several groups that wanted to apply the techniques of molecular and cell biology to studying human disease. The idea was to provide a critical mass of both clinical and nonclinical scientists who could share common technology and equipment, and interact closely with each other. It was hoped that this would produce the kind of environment in which young clinical scientists would thrive and which would also be attractive to basic scientists. The MRC, though enthusiastic, was unable to fund the whole project, but in the end the building was established through the generous support of the MRC, Imperial Cancer Research Fund, Wolfson Foundation, E. P. Abraham Research Fund of the University of Oxford, Wellcome Trust, and Nuffield Medical Trustees, University of Oxford. A very attractive building (Fig. 1) was formally opened by HRH The Princess Royal in July 1989.

The Institute contains four floors of research laboratories and a fifth floor, which has a large and pleasant area for the staff together with a library and seminar and conference rooms. The groups share larger equipment and facilities, and there is a central administration to coordinate the running of the Institute and its funding.

Originally, the idea was to house approximately 250 young scientists in the Institute, but its work has gone well and it now has 16 groups and over 400 staff. Each of the groups works on problems related to the particular research interests of its parent department. They are all selffunded and obtain their research support from the MRC, the medical charities, or other bodies that support biomedical research. A few of the staff have permanent university appointments, but the vast majority are funded by research grants. The Institute is run in the form of a "research hotel." While a group's science is going well and it can raise its own funds, it stays in 


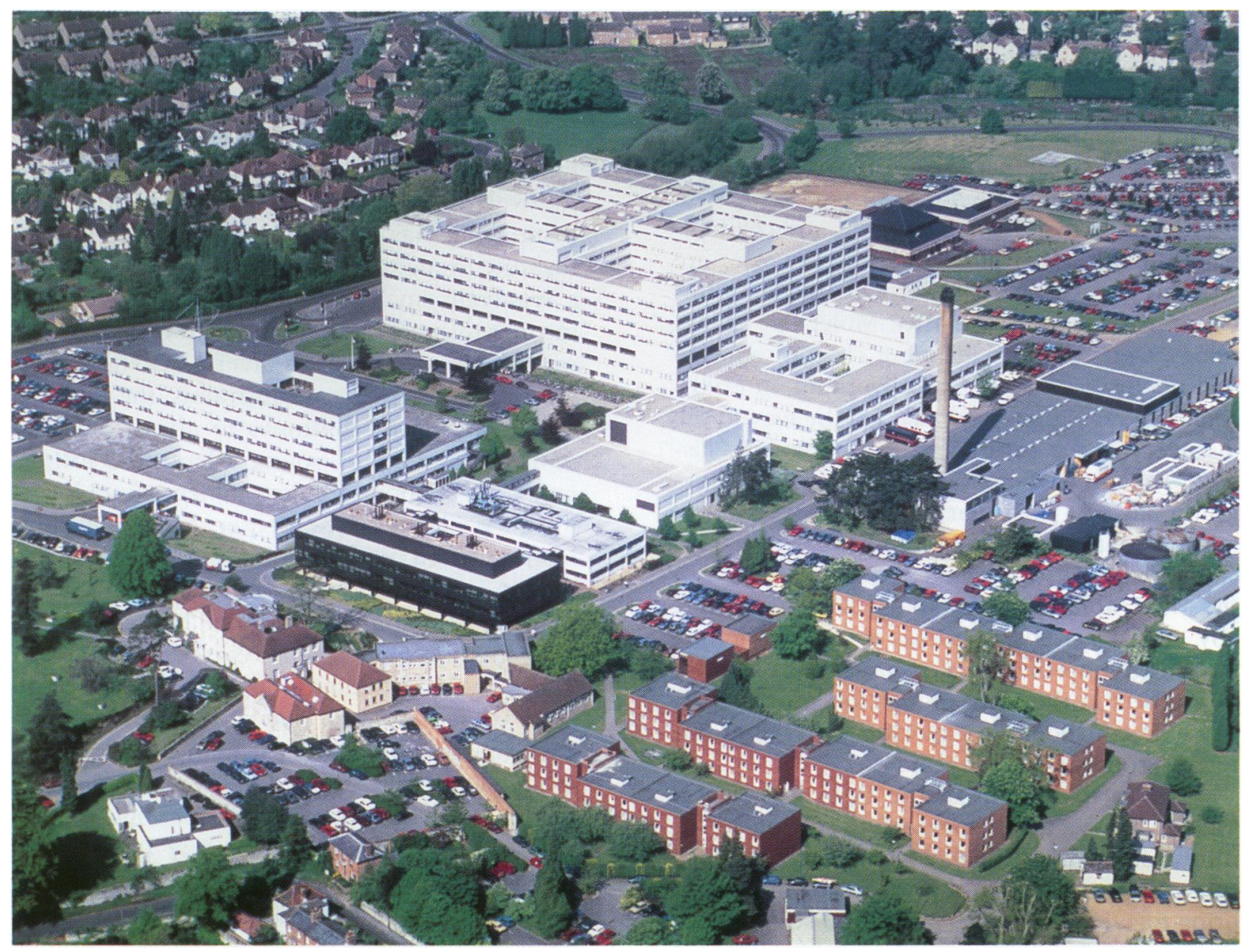

FIG. 1. The Institute of Molecular Medicine, University of Oxford, Oxford, United Kingdom

the building; should its work decline for any reason, the group disbands and any remaining scientists return to their parent department in the Oxford Clinical School. It is hoped that in this way the Institute will not decline as its staff age, and it will continually refresh itself.

Over the first 5 years of its life, the Institute has already made a number of major contributions to medical knowledge. Work in the Institute has led to the discovery of a number of genes for common inherited diseases. Recently, for example, its scientists have announced the discovery of the gene for polycystic kidney disease, one of the most common inherited conditions in this country. New causes of mental retardation have been discovered, promising methods for the treatment of genetic disease and cancer by gene therapy are being developed, major progress has been made towards a better understanding of the reasons why acquired immunodeficiency syndrome (AIDS) is proving so intractable, and a completely new system whereby the body responds to oxygen in the environment has been unearthed. Mechanisms have been defined by which viral antigens are processed and transferred to the surface of cells to be recognized by cells of the immune system. Important progress has been made towards an understanding of the genetic basis for susceptibility or resistance to common infections, notably malaria, work, which has opened new possibilities for vaccine production. Work at the Institute has been recognized by a number of international prizes and medals. Four of the scientists in the Instituic are already Fellows of the Royal Society, an unusual distinction in the more clinical areas of medical research. And it is already attracting a number of first class young scientists back from the United States.

But perhaps the most important question is whether the total output of the Institute is greater than the sum of its individual parts. In 
other words, has it succeeded in its aim in stimulating interactions between scientists with different interests and backgrounds? Collaborative programs have been developed for gene therapy in cystic fibrosis through interactions between members of the Imperial Cancer Research Fund (ICRF) groups interested in transport systems in bacterial and mammalian systems, and cell biologists in the Department of Pediatrics who are working directly on cystic fibrosis. Collaborations between workers in the MRC Molecular Hematology Unit who are mapping chromosome 16 and nephrologists who were working on erythropoietin regulation have opened the way to the discovery of the gene for polycystic kidney disease. The establishment of a small yeast genetics group has had particular value, and several important collaborative programs have evolved, including studies of human recombination with the MRC Molecular Hematology Unit, gene therapy, and a variety of studies involving cloning large fragments of DNA. Gene mapping expertise of workers in the ICRF groups has provided invaluable collaborative expertise for several different groups in the Institute.

The establishment of the IMM was a new and we believe novel approach to solving a genuine problem in the field of biomedical science in this country. In essence, it was an attempt to bring together the basic and clinical sciences under one roof and to provide an environment where the complexities of the molecular sciences could be applied to clinical problems and where young people from a wide background of disciplines and countries could be introduced to this increasingly important field. We believe that it has been a successful enterprise, and, as judged by its research income, this belief is shared by the major funding bodies. It is, however, more difficult to raise funds for essential core activities of the Institute, largely because of the way the funding bodies operate in the United Kingdom. As experience has been gained in running the Institute, it has become apparent that for the Institute to succeed in the long term it must have a relatively small but secure source of flexible income to meet the many and unexpected demands that arise from its diverse activities.

In spite of financial constraints, the future is bright. The IMM continues to attract a highly motivated group of young scientists. Furthermore, negotiations are now under way to link it to the Wellcome Gene Center, a new development initiated by Professors John Bell and Peter Morris, which will focus on researching the genetics of common, multifactorial human disease, with funding support from the Wellcome Trust. The combined buildings will be integrated to form what should be one of the most exciting basic biomedical science facilities in Europe. As groups continue to transfer in and out of the Institute, further opportunities for collaboration will arise. For one, Professor Kay Davies, currently head of molecular genetics in the IMM, has recently been appointed Professor of Genetics at the University of Oxford and will continue to work closely with us.

Finally, we support the international growth of molecular medicine and particularly welcome the establishment of a global Molecular Medicine Society. 